\title{
PERENCANAAN KOMUNIKASI PEMASARAN DAN PENJUALAN PERSONAL
}

\author{
Hanan Fakhira Sa’diyyah \\ Naura Aulia Hafidzah \\ Muhammad Zaidan Mubarak \\ Mumuh Mulyana \\ Sofie Kurnia Asih
}

Selamat berjumpa lagi. Saat ini Anda sudah memasuki materi inisiasi V yang akan membahas materi Perencanaan Komunikasi Pemasaran dan Penjualan Personal. Untuk itu Anda harap mempelajari modul 5 dan 6 dari BMP Perencanaan Pemasaran (EKMA 4569). Jangan lupa untuk mengerjakan tes formatif modul 5 dan 6 untuk mengevaluasi kemampuan pemahaman Anda tentang materi tersebut.

Kompetensi Umum

Kompetensi Khusus
: Mahasiswa diharapkan mampu memahami dan menjelaskan konsep dasar dan perancangan perencanaan pemasaran serta aplikasinya dalam bauran pemasaran

: Mampu menjelaskan dan melakukan Perencanaan Komunikasi Pemasaran dan Penjualan Personal

Menjelaskan Perencanaan Komunikasi Pemasaran

Menjelaskan Bentuk Komunikasi Pemasaran

Menjelaskan Perencanaan Program Periklanan

Menjelaskan Bentuk Promosi Penjualan

Menjelaskan Peran Strategis Promosi Penjualan

Menjelaskan Perencanaan Program Hubungan Masyarakat yang efektif

Menjelaskan Perencanaan Penjualan Personal

Menjelaskan Peran Penjualan Personal

\section{Sumber Belajar}

1. Utama

Modul 5 dan Modul 6 EKMA4569

Perencanaan Pemasaran. Daniel Tumpal. Universitas Terbuka. 2016

2. Tambahan:

- Marketing Management : A Strategic Decision-Making Approach. John W. Mullins and Orville C. Walker, Jr. $7^{\text {th }}$ edition. McGraw-Hill International Edition. 2010 
- Advertising \& Integrated Brand Promotion. Thomas C. O'Guinn, Chris T. Allen and Richard J. Semenik. $5^{\text {th }}$ Edition. South-Western Cengage Learning. 2009.

\section{Rangkuman Materi Kuliah}

Perencanaan Komunikasi Pemasaran

Untuk mencapai sasaran pemasaran, perusahaan perlu berkomunikasi dengan pelanggannya, baik pelanggan lama maupun pelanggan potensial. Komunikasi tersebut dapat digolongkan menjadi :

- Komunikasi impersonal, contohnya iklan, display di titik penjualan, promosi penjualan, media elektronik, dan humas.

- Komunikasi personal (atau orang-ke-orang langsung), contohnya pertemuan langsung antara wiraniaga dengan pelanggan di pusat penjualan dan pusat informasi.

Perusahaan memiliki beragam teknik komunikasi yang dapat digunakan secara sendirisendiri atau kombinasi (baur komunikasi). Semuanya bergantung pada situasi, terutama anggaran agar didapatkan efek komunikasi yang maksimum.

Pengembangan program periklanan melibatkan lima tahap. Pertama, pengiklan perlu menetapkan sasaran iklan; kedua, mereka harus menetapkan anggaran yang memperhitungkan tahapan siklus hidup produk, pangsa pasar dan basis konsumen, persaingan, frekuensi iklan dan tingkat substitusi produk. Ketiga, mereka harus memilih pesan iklan, menentukan bagaimana pesan dihasilkan. Keempat, mereka harus memutuskan media yang akan digunakan. Keputusan ini mencakup memilih jangkauan, frekuensi dan dampak yang diinginkan, lalu memilih media yang membawa pesan tersebut.

Promosi penjualan merupakan kiat-kiat insentif yang sebagian besar bersifat jangka pendek. Promosi penjualan dirancang untuk merangsang pembelian produk/jasa tertentu yang lebih cepat dan/atau lebih banyak oleh pelangan. Promosi penjualan menawarkan insentif untuk membeli. Promosi penjualn dibedakan menjadi promosi konsumen, promosi perdagangan, dan promosi bisnis dan wiraniaga. Contoh promosi perdagangan adalah potongan harga, tunjangan iklan dan pajangan, dan barang gratis; contoh promosi bisnis dan wiraniaga adalah pameran perdagangan dan konvensi, kontes bagi wiraniaga dan iklan khusus. Dalam menggunakan promosi penjualan, perusahaan harus menetapkan tujuan, memilih kiat, mengembangkan program, mengujicoba, menerapkan dan mengendalikannya, serta mengevaluasi hasilnya. Promosi penjualan berhasil meningkatkan penjualan dan pangsa pasar jangka pendek tetapi tidak berpengaruh untuk jangka panjang.

Hubungan masyarakat melibatkan berbagai program yang dirancang untuk mempromosikan dan/atau menjaga citra perushaan atau tiap produknya. Kiat utama humas adalah publikasi, peritiwa, berita, pidato, kegiatan pelayanan masyarakat, dan media identitas. Dalam mempertimbangkan kapan dan bagaimana menggunakan humas, manajemen harus menetapkan tujuan pemasaran, memilih pesan dan sasaran humas, menetapkan rencana tersebut dengan hati-hati dan mengevaluasi hasilnya. Hasil penerapan program dievaluasi dalam bentuk 
besarnya paparan dan penghematan biaya, perubahan kesadaran/pengertian/sikap, dan kontribusi penjualan dan laba.

\section{Perencanaan Penjualan Personal}

Penjualan personal adalah bagian dari bauran komunikasi yang memberi kesempatan pertemuan orang ke orang antara wakil perusahaan dengan pelanggan atau pelanggan potensial. Secara tradisional, perusahaan telah memiliki tenaga penjualan jauh sebelum ia memiliki kegiatan pemasaran formal. Bagian anggaran yang dihabiskan untuk tenaga penjualan dalam suatu perusahaan kebanyakan lebih besar dibandingkan untuk gabungan periklanan dan promosi. Walaupun merupakan bagian kunci dalam bauran pemasaran, departemen penjualan sering masih bertindak terlepas dari pemasaran. Karenanya seringkali dalam mencapai sasaran jangka pendek, penjualan personal gagal menyelaraskan bauran produk dan pasar dengan sasaran pemasaran strategis. Dalam menetapkan peran tenaga penjualan, harus dipahami terlebih dahulu tahapan-tahapan dalam pembelian. Tahapan tersebut adalah pengenalan masalah, pencarian informasi, evaluasi alternatif, penentuan pembelian, dan pembelian ulang. Tenaga penjualan dalam melakukan tugasnya tidak harus dilakukan dengan kunjungan personal tapi dapat digantikan dengan alternatif kegiatan lain sehingga informasi yang dibutuhkan calon pelanggan tetap dapat disampaikan. Keuntungan penjualan personal dibandingkan dengan unsur lain dalam bauran komunikasi adalah komunikasi dapat dilakukan dua arah, wiraniaga dapat memanfaatkan pengetahuan produk dengan semaksimal mungkin, dan ia dapat langsung meminta pemesanan.

Pada dasarnya aktivitas seorang wiraniaga dibagi menjadi tiga, yaitu:

1. melakukan komunikasi telepon;

2. melakukan perjalanan;

3. menjalankan fungsi administrasi .

Beban kerja seorang wiraniaga harus dianalisis untuk menetapkan jumlah tenaga penjualan yang dibutuhkan dan dapat mengalokasikan daerah kerja dengan lebih seimbang.

Tenaga penjualan harus mencapai sasaran yang sejalan dengan sasaran pemasaran, yaitu dalam hal:

1. berapa banyak yang dijual (volume);

2. apa yang dijual (campuran produk);

3. dimana dijual (segmen pasar);

4. anggaran yang diperkenankan;

5. marjin profit.

Selain sasaran kuantitatif seperti disebut di atas, terdapat juga sasaran kualitatif yang harus dicapai tenaga penjualan. Namun demikian harus dihindari menetapkan sasaran kualitatif yang subyektif. Sasaran yang ditetapkan harus tetap dapat terukur. Contohnya mengukur kemampuan tenaga penjualan mengaplikasikan pengetahuan produk pada pekerjaannya, atau kemampuan mereka merencanakan pekerjaan mereka, atau kemampuan mereka mengatasi keberatankeberatan pelanggan selama wawancara.

Walaupun terlihat sangat disederhanakan, aktivitas kunci manajemen dapat disimpulkan sebagai berikut : 
1. penetapan standard performa (baik kuantitatif dan kualitatif);

2. pemantauan pencapainya menurut standar ini;

3. pelatihan bagi yang tertinggal;

4. penetapan iklim motivasi yang sesuai.

Untuk memaksimalkan performa, harus ada keseimbangan antara insentif dan disinsentif. Yang merupakan bagian dari insentif adalah :

1. imbalan sesuai dengan performa;

2. pemberian pujian dan penghargaan;

3. kebosanan dan keadaan monoton seminimal mungkin;

4. kebebasan dari rasa takut dan cemas;

5. perasaan memiliki;

6. perasaan telah melakukan pekerjaan yang berguna.

Rencana penjualan adalah penerjemahan dari target individual tenaga pemasaran dengan turut mempertimbangkan faktor-faktor tertentu seperti ukuran teritori, jumlah pelanggan dalam teritori tersebut, dan lain-lain.

Referensi :

[1] Tumpal, Daniel, 2016. Perencanaan Pemasaran. Universitas Terbuka.

[2] McDonald, Malcolm and Wilson, Hugh. 2011. Marketing Plans: How To Prepare Them, How To Use Them. $7^{\text {th }}$ edition. Wiley.

[3] Mullins, John W. and Walker, Jr. Orville C., 2010. Marketing Management : A Strategic Decision-Making Approach. $7^{\text {th }}$ edition. McGraw-Hill International Edition.

[4] O'Guinn, Thomas C.; Allen, Chris T. and Semenik, Richard J., 2009. Advertising \& Integrated Brand Promotion. $5^{\text {th }}$ Edition. South-Western Cengage Learning.

[5] Crawford, Merle and Benedetto, Anthony Di 2011. New Products Management. 10 ${ }^{\text {th }}$ Edition. McGraw-Hill International Edition. 2011.

[6] Mulyana, Mumuh. 2019. "STRATEGI PROMOSI DAN KOMUNIKASI." INA-Rxiv. June 12. doi:10.31227/osf.io/v7dfr.

[7] Mulyana, Mumuh. 2019. "MENGANALISIS PERILAKU KONSUMEN.” INA-Rxiv. June 12. doi:10.31227/osf.io/2wj34.

[8] Mulyana, M., 2012. Consumer Behaviour: Sukses Dengan Memahami Konsumen.

[9] Mulyana, M. and Sulistiono, S., 2012. Kewirausahaan: The Long Life Way of Business.

[10] Pauziah, P. and Mulyana, M., 2018. Formulation of The Green Marketing Development Strategy for the Body Shop Botani Square Bogor. In THE INTERNATIONAL CONFERENCE ON ACCOUNTING AND MANAGEMENT SCIENCE (p. 171).

[11] Hidayat, L., Mulyana, M. and Effendy, M., 2018. Membangun Kepuasan Mahasiswa Pengguna Laboratorium Komputer. JAS-PT Jurnal Analisis Sistem Pendidikan Tinggi, 1(2), pp.93-101.

[12] Mulyana, M., PERSEPSI DAN PERILAKU KONSUMEN TERHADAP ONLINE SHOPPING. 